\title{
Las técnicas multivariadas de análisis y predicción en psicología del trabajo
}

\section{José M.a Prieto Zamora}

Universidad Complutense

Departamento de Psicología Diferencial

\section{INDICE}

1. Una perspectiva fundamentalmente diferencial $\ldots \ldots \ldots \ldots \ldots$

2. El enfoque psicométrico multi-

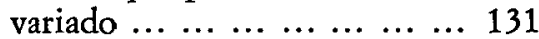
a) Cuadro de datos básicos... 131
b) Configuración de matrices

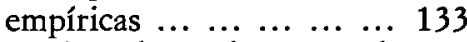
c) Análisis de predicción múl. $\begin{array}{llllllll} & \text { tiple } & \ldots & \ldots & \ldots & \ldots & \ldots & \ldots\end{array}$
d) Análisis dimensional o de $\begin{array}{lllllll}\text { factores } & \ldots & \ldots & \ldots & \ldots & \ldots & 137\end{array}$

3. Predicción centrada en la per-

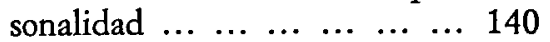

a) Ajuste de perfiles ....... 141

b) Ecuación de especificación. 142

4. Criterio y validez en Psicología del Trabajo ... ... ... ......... 145

a) Criterio $\ldots \ldots \ldots \ldots \ldots \ldots$

b) Validez $\ldots \ldots \ldots \ldots \ldots \ldots .146$

5. Psicología Diferencial y Psicología de las Organizaciones ... 148

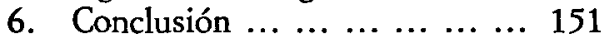

7. Referencias .............. 151

\section{UNA PERSPECTIVA} FUNDAMENTALMENTE DIFERENCIAL

En junio de 1980 se celebraron una serie de reuniones en el Colegio de Doctores y Licenciados en Psicología de Madrid con vistas a delimitar y clarificar el campo de actuación peculiar del psicólogo. Se puso de relieve, una vez más, la desconexión entre el bagaje académico, más o menos válido, del recién titulado que se dispone a plantear batalla en la psicología aplicada y los requerimientos predominantemente funcionales y operativos que la sociedad le demanda.

Así, al intentar definir qué era un «psicólogo" se puso en evidencia la innegable bifurcación de caminos que conduce a planteamientos y esquemas de trabajo de difícil encaje mutuo. Quienes resaltaban los presupuestos científicos del quehacer psicológico dejaban constancia de su desconcierto al escuchar las metas y procedimientos habituales de trabajo que exponían los psicólogos aplicados. Estos, a su vez, manifestaban su descontento ante la docta sapientia de aquéllos, recurriendo al famoso retintín orteguiano de «no es esto, no es esto». 
$\mathrm{Y}$ de hecho, especialmente en lo que concierne a la Psicología del Trabajo (de la Industria, de las Organizaciones...) se observa que muy poco de sus avances y resultados se integra en el acervo de conocimientos exigidos por los sucesivos «planes de estudio» e incluso por los contenidos de la mayoría de las asignaturas. Así «Psicodiagnóstico» se ocupa de pasada de los problemas inherentes a la selección, promoción y clasificación de plantillas; todo lo más, hace una mención a título gracioso. De la misma manera, en Motivación se aborda raramente el estudio de los modelos cognitivos de Vroom (1964), Porter y Lawler (1968), las necesidades humanas en la Organización de Aldefer $(1969,1972)$, los factores extrínsecos e intrínsecos de la motivación (Herzberg, 1959, 1968) y la satisfacción (Forteza, 1971), así como los estudios multivariados de Cattell (1957), Horn (1966), Cattell y Child (1975) verificados a partir de poblaciones adultas en su medio de trabajo. También, muy ocasionalmente en Psicopatología se hace el suficiente énfasis respecto a la incidencia de las condiciones laborales en el desarrollo y manifestación de los distintos desajustes comportamentales. En lo que concierne a la estructura de la inteligencia, son contadas las citas a los trabajos de Fleishman $(1964,1967)$ sobre el desempeño laboral, de Dunnette $(1966,1976)$ sobre los requerimientos aptitudinales de los puestos de trabajo o los enfoques taxonómicos de McCormick $(1960,1972)$ a partir de los análisis de tareas. La lista de deficiencias sería interminable y no es éste precisamente el lugar para abundar en ello.

¿Cabe hablar, en este contexto, de dos tipos de psicólogos? Unos subrayan la Psicología como ciencia que avanza a través de las variables controladas en el laboratorio o bien mediante enfoques multivariados de los problemas de más amplio espectro. Otros la entienden como «saber hacer» y desenvolverse ante los problemas concretos para los que la teoría científica no tiene previstas aún soluciones, alternativas o procedimientos tan viables como coherentes. Incluso, to mando prestados conceptos y connotaciones, ¿sería pertinente hablar de los primeros como «académicos de la psicología» y de los segundos como «profesionales de la psicología»? Ciertamente, este desplazamiento de metas y fines está ahí y no debe ser soslayado.

Ahora bien, ¿no se constata otro tanto en los mismos presupuestos de la psicología teórica? Se percibe un cierto agostamiento de los temas de estudio (y de los tratamientos experimentales bivariados) porque no pueden dar mucho más de sí; el ser humano no es un mero organismo reactivo ni se expresa a través de automatismos igualitarios, equipotentes o compulsivos; desde la biología lo prioritario son las diferencias, el pensamiento simbólico y la involucración sistemática y activa de la personalidad (von Bertalanffy, 1967). Por ello, las teorías multidimensionales y las teorías cognitivas están ganando posiciones, pero mediante una sofisticación metodológica tal que sus modelos y resoluciones apenas si hallan eco entre los no iniciados. Unicamente el nuevo énfasis del psicodiagnóstico en torno a la pertinencia de análisis prioritariamente situacionales está marcando pautas manejables y útiles en psicología aplicada; ahora bien, con todos los inconvenientes que la multiplicidad de ambientes retrotrae para una decantación teórica consistente.

La psicología industrial abrió su propia brecha siguiendo patrones muy similares a los del diagnóstico tradicional. De hecho, la mayoría de los pioneros ponían el énfasis en técnicas y aplicaciones de corte predominantemente psicométrico. Teniendo en mente las diferencias individuales se buscaba la adecuación del hombre al puesto, desarrollándose muy numerosos métodos para la predicción del rendimiento, así como la clasificación y valoración de puestos y personas, como se trasluce en una revisión somera de los artículos publicados en el Journal of Applied Psychology o en Personnel Psychology. Tras una profunda crisis, cuya reseña sucinta puede leerse 
en el libro de Korman (1971), ha madurado una redefinición de su contenido en cuanto «psicología del trabajo». Con este cambio de denominación, de raigambre más bien centro-europea, se pretende destacar la preocupación por los problemas psicosociales que se derivan de la complejización automatizada de los puestos de trabajo, así como la necesidad de una humanización progresiva del medio laboral, dando lugar a nuevos «roles», exigencias y ambientes.

Desde esta perspectiva, el ámbito de incidencia se abre en paralelo al abanico estructural que deslinda, por su parte, la Sociología Económica: la humanización en el sector primario (centrado en la producción de materias primas y energéticas), en el sector secundario (que agrupa a todas las industrias de transformación y en el que la iniciativa y logros del psicólogo gestó una Psicología Industrial), y en el sector terciario (que adscribe todas las empresas de servicios y en cuyo seno se han generado la mayor parte de los recientes estudios en Psicología de las Organizaciones).

Ahora bien, en estos tres sectores los avances han sido posibles porque los psicólogos-profesionales se han ocupado, más bien, en la investigación, desarrollo y aplicación de técnicas psicológicas en relación con tres tipos diferenciados de problemas:

a) Los que surgen de la interacción hombre-máquina en un puesto dado de trabajo.

b) Los que se suscitan a partir de las relaciones interpersonales $y$ laborales en el colectivo de trabajadores.

c) Los que se derivan de la inserción del individuo en una organización y del modo como ésta obtiene un rendimiento productivo.

Ciertamente estos psicólogos nunca han tenido que «inventarse» los temas objeto de estudio; en muy contadas ocasiones han podido cercenar estos problemas con metodologías tomadas prestadas del laboratorio; mayoritariamente han tenido que ocuparse de ellas siguiendo estrategias de aproximación y decantación que han tomado prestadas de la Psicología Diferencial.

La gama de funciones y tareas que han debido asumirse desbordan una mera exposición sucinta; no obstante, y siguiendo en parte el esquema de V. Pérez Velasco (1980), pueden desglosarse así:

1. Funciones en relación con la organización: conflicto entre grupos de trabajo, conflicto hombre-organización, tratamiento de las tensiones sociales, estudios sobre liderazgo y ambiente de trabajo, cauces de información-comunicación, etc.

2. Funciones en relación con las técnicas de producción: estudios sobre motivación y satisfacción laboral, cambios en los sistemas de trabajo, ingeniería humana y ergonomía, abordamiento del absentismo y la accidentabilidad, el error y el fallo humano, etc.

3. Funciones en relación con las técnicas de personal: selección, formación, gestión y previsión de plantillas (diseño de carreras, seguimiento, evaluación e inventarios de recursos humanos), salarios e incentivos como motivación, seguridad e higiene, etc.

4. Funciones en relación con el bombre como individuo: tratamiento de casos concretos, orientación profesional, ajuste persona-puesto, asesoramiento psicológico personal, etc.

5. Funciones en relación con la imagen externa: estudios de campo, imagen social de la empresa, actitudes hacia el consumo, idoneidad de campañas publicitarias, disonancia cognoscitiva, imagen e identidad interna de la empresa, competitividad y estudios de refuerzo al mercado, etc.

Sin lugar a dudas, los psicólogos académicos, absortos en la parsimonia de sus investigaciones de laboratorio, se li- 
mitaron a brindar ciertas conclusiones científicas como elementos o conceptualizaciones de referencia, obviando involucraciones con metas y resultados en plazos prefijados. De ahí la disyuntiva constatada más arriba y que hoy parece poder resolverse merced a la simbiosis entre Psicología Diferencial y las metodologías multivariadas.

Las páginas que siguen van a delinear los modelos teóricos, así como algunos de los procedimientos empíricos que permitirán un enfoque científico-profesional en el amplio cúmulo de tareas que suele absorber y ocupar al psicólogo del trabajo. Todo ello puede hacerse centrándose en un criterio clave, tanto en la órbita pública como privada, y que desde sus inciertos orígenes ha guiado los esfuerzos, observaciones y constataciones de los psicólogos diferenciales: el rendimiento a través de los logros. En otros contextos se alude a este criterio, como si de una novedad psicológica se tratara, con un término tan rebuscado como sugestivo: «validez ecológica» (Claxton, 1980).

\section{EL ENFOQUE PSICOMETRICO MULTIVARIADO}

\section{A) Cuadro de datos básicos}

Desde hace quince años el profesor R. B. Cattell $(1966,1978,1979)$ viene propugnando un modelo comprehensivo en Psicología, expresado mediante ejes cartesianos, que recoge todas las fuentes de variabilidad experimental y observacional. Este esquema explicativo ha sido denominado «cuadro de Datos» $\mathrm{o}$ «Matriz de Relaciones» Básicas. Cinco son los ejes de referencia que deben ser tomados en consideración al abordar exhaustivamente cualquier hecho psicológico: las personas, los estímulos, las respuestas, las situaciones y los observadores (cuya identificación mnemotécnica puede ser PERSO). Viene a ser una ampliación de su Mapa de Covariaciones propuesto en
1946, que aparece frecuentemente citado entre los psicólogos teóricos de orientación multivariada.

Hasta el presente este «cuadro de Datos» ha sido tomado en consideración únicamente por los investigadores en psicología de la personalidad (en su sentido más lato), pero puede brindar un marco de coherencia al quehacer habitual del psicólogo del trabajo.

En primer lugar, el psicólogo que presta su servicio en empresas sabe que tiene que tratar fundamentalmente con personas. Estas constituyen la plantilla de los trabajadores y su desempeño laboral viene demandado por los problemas que suscita la convivencia y actividad en grupos. De entrada sabe que el colectivo de trabajadores constituye, generalmente, una muestra sesgada respecto a la población total, por muy grande que sea la empresa. Este hecho no suele ser subrayado con suficiente énfasis $y$, por ende, las conclusiones a que se adviene deben ser asumidas con matizaciones. Pero a su vez esa plantilla está sesgada también en función de categorías, titulaciones o cualificaciones exigidas, desempeños especializados, tareas, centros de trabajo, localización geográfica, edad, sexo, etc. Por ello el psicólogo del trabajo, tras la euforia inicial, suele hallarse transitoriamente extraviado ante tanta peculiaridad, especialmente al elegir instrumentos de predicción o diagnóstico. Así, en los manuales de pruebas disponibles, los baremos corresponden a núcleos de población, más o menos amplios, que no encajan a cabalidad con la muestra concreta que le ocupa. De ahí el recato con que debe entenderse cualquier tipo de puntuaciones normalizadas de cara a un pronóstico - evaluación dada. Es ésta, pues, una de las fuentes de variación que debe ser sopesada atentamente a la hora de planificar cualquier actuación profesional específica.

En el ámbito laboral cada puesto de trabajo y sus exigencias vienen a ser los estímulos ante los que el empleado debe mostrar su idoneidad y buen hacer. De hecho, uno de los primeros objetivos de 
los psicólogos industriales a principios de siglo consistió en estudiar a fondo cada tarea, sus características, modos de ejecución, tiempos mínimos y máximos, requerimientos, etc. Ahora bien, excepto en las cadenas de producción (en que cada paso está meticulosamente detallado y previsto, como ocurre especialmente en el sector secundario), en la mayoría de los puestos (sectores primario y terciario) se cuenta con una descripción somera de los mismos, por lo que su aprendizaje y dominio es más una cuestión de experiencia o de captación in situ. Es más, dado el continuo auge de los cambios tecnológicos y sociales, las características de cada puesto se transforman con notable buen ritmo (como puede comprobarse, por ejemplo, en empresas de servicios tras una lectura de los manuales que suministra el Departamento de Organización y lo que observa el psicólogo que se desplaza a un centro determinado). Este hecho plantea otra fuente de variación a la hora de procurar una predicción hombre-puesto a partir de las diferencias individuales. Como la línea en un espacio geométrico, el puesto suele quedar descrito en la mera coincidencia de planos, por lo que su decantación precisa (a la hora de efectuar la regresión hacia un criterio) puede resultar harto ambigua.

Las respuestas vienen a coincidir con la ejecución acertada, a través de una minimización de los fallos (y cuyo aprendizaje no puede reducirse a una cadena de «ensayos y error», asociaciones, contigüedad) y merced a la involucración personal del trabajador que asimila integradoramente su tarea y su persona (pudiendo servir de ejemplo para lo que ahora se conoce como «aprendizaje estructurado»). Son estas respuestas y desempeños eficaces los que determinan parcialmente el nivel global del rendimiento individual o grupal. Ahora bien, también aquí la valoración de la ejecución lograda no es un tema preciso ni diáfano. Los trabajos en cadena suelen contar con unas pautas de respuesta que se consideran adecuadas merced a criterios externos y que igualmente suelen ser objeto de cambios, mientras que en las tareas propias del sector terciario la fijación de los aciertos o errores suelen estar supeditados a aspectos ajenos al sujeto (una buena gestión comercial que se malogra por la demora en los pagos por parte del cliente), así como a cambios en la política de la dirección o alzas de calidad en la competencia. Por tanto, en unas categorías laborales la predicción del rendimiento puede establecerse en razón directa a una ejecución dada, mientras que en otras no están del todo claros los procedimientos a seguir para su perfilación objetiva. ¿Criterios simples, compuestos o ponderados? Pueden leerse en Blum y Naylor (1968) los distintos tratamientos disponibles al respecto.

En cuarto lugar, la situación y ambiente de trabajo está supeditada a la organización empresarial misma. Haciendo referencia únicamente a las teorías $\mathrm{X}$ e Y (McGregor, 1960), por ejemplo, se comprueba la diferencia de marco de actuación del empleado de cara a un rendimiento, según los niveles de iniciativa y responsabilidad de que disfrute. Hasta hace escasamente veinte años la mayoría de las predicciones se llevaban a término considerando a la empresa como una especie de vacío irrelevante. Actualmente, en cambio, Argyris (1961, 1964), Likert (1967) y Schein (1965) y todos los que ponen el énfasis en una psicología de las organizaciones, plantean que nada se puede intentar en el ámbito del trabajo humano si no se lleva a cabo una comprehensión global de la conducta en el marco referencial de la organización. Señalan que es preciso investigar cuáles son los niveles óptimos de iniciativa e interacción permitidos, qué tipo de planificación y participación en los objetivos está prevista y cómo fluye la información y se transmite la comunicación; recalcan que toda predicción útil debe cernir las peculiaridades del sistema en que cada contratado se desenvuelve antes de abordar las características transitorias del puesto. De hecho, una de las comprobaciones más evidentes consiste en que toda organización logra absorber cua- 
lesquiera diferencias individuales se den en sus empleados, especialmente a largo plazo, ya que integra a unos o margina a otros, no tanto en función de sus aptitudes, sino merced al grado de ajuste o asimilación con que el individuo acepte los esquemas tácitos de funcionamiento interno predominantes. Es más, en las grandes empresas no cuenta tanto la productividad individual cuanto la globalizada, pues la supervivencia de la misma depende prioritariamente del conjunto (propiciando incluso actividades en vía muerta en previsión de futuro). A su vez, la empresa, como organización, está interconectada con multitud de sistemas organizados competitivos con los que forma el entramado económico social. Es este eje otra fuente de variabilidad que el psicólogo del trabajo debe manejar a la hora de situar su marco de actuación.

Cuando se menciona al observador, el psicólogo medio suele limitarse a pensar en datos $L$ y dar la cuestión por zanjada. No obstante, este eje trasciende esta alusión, intentando incorporar al ámbito psicológico el tema de la relatividad del observador. Son muchos los observadores que intervienen en la esfera laboral a la hora de fijar el rendimiento de una ejecución:

a) El psicólogo mismo, pues aun cuando se sitúe al margen de la organización está sesgando la misma recogida de datos.

b) La dirección de la empresa ante quien se debe demostrar la eficacia de los procedimientos y evaluaciones y que, a su vez, está involucrada al haber tenido que tomar decisiones conexas con su papel en la organización.

c) Los mandos medios en cuanto ejecutores y responsables de los programas en curso y en cuanto pantallas de rebote a la hora de los conflictos, errores y fracasos.

d) El comité de empresa y los delegados sindicales por su peculiar papel de canalizadores y a la par de incitadores de disonancias, ajustes-desajustes, valores socia- les, presiones de grupo y conflictos.

e) Los trabajadores mismos en calidad de conocedores de su propia labor, así como de la de sus compañeros, generando pactos y normas internas funcionales propiciadoras de un cietto tipo de homeostasis productiva.

A primera vista el panorama parece haberse complicado en exceso. $Y$, sin embargo, esta dimensionalización de las fuentes de variabilidad permite poner un cierto orden, ya que facilita la confluencia entre el psicólogo-académico y el psicólogo-profesional a la hora de orientarse y fijar estrategias con que afrontar la parcela de realidad que les incumbe.

\section{B) Configuración de matrices empíricas}

Una de las peculiaridades de la estadística multivariada consiste en que, para simplificar el abordamiento matemático de los datos, se estructuran éstos según los patrones de una matriz algebraica. Uno de los ejemplos más comunes es la típica acta de notas de clase. En cada fila horizontal se sitúan el nombre de cada alumno; en cada columna vertical se reseña el título de la asignatura y cada una de las casillas de cruce recoge la información cuantitativa o cualitativa pertinente: los datos.

Ciertamente dentro del enorme cúmulo de temas de que se ocupa el psicólogo del trabajo algunos pueden abordarse mediante enfoques cuantitativos, otros mediante meras reseñas cualitativas y unos pocos, en fin, barruntarse a través de conceptualizaciones o interpretaciones que se desgajan con perspicacia a partir de hallazgos o constataciones psicológicas más generales. Van a dejarse de lado en esta exposición aquellos temas que sólo permiten un tratamiento cualitativo $o$ interpretativo, para centrarse en aquellos que admiten un tratamiento cuantitativo multivariado. 
Los análisis multifactoriales intentan extraer las relaciones que conectan las distintas variables entre sí - poniendo de relieve lo que tienen mutuamente de relativo - merced a la información suministrada por una muestra representativa, y que intervienen como canalizadores o referentes de la variabilidad. Se han subrayado estos dos términos (relativo y referente) porque la estructura factorial que se obtiene en un determinado análisis es relativa (o pertinente) a las correlaciones ínter-variables (reseñadas a lo largo de las columnas) y es peculiar de la muestra de sujetos que intervienen como referentes que suministran información (en las sucesivas filas). Ahora bien, en un momento dado (cuando, por ejemplo, se cuente con más variables que sujetos) se puede transponer la matriz (las variables en las filas y los sujetos en las columnas) de suerte que los sujetos intervengan como relativos y las variables como referentes. Este tipo de transposiciones puede resultar especialmente eficaz cuando en vez de dimensionalizar un tema se prefiera establecer tipologías o clasificaciones dimensionalizadas de los sujetos.

Así las cosas, es posible esbozar diez diseños diferentes útiles en psicología del trabajo tomando como punto de partida los cinco ejes ya comentados del cuadro de datos, según se bosqueja escuetamente en la tabla 1.

Evidentemente alguno de los estudios propuestos en esta tabla desbordan los límites de la psicología entrando de lleno en lo que últimamente se está denominando «psicosociología del trabajo» (P. Domínguez, 1979), de ahí la cautela con que deberán extraerse posibles conclusiones: parece más una tarea de equipo que singladura individual.

TABLA 1

Algunas aplicaciones del Cuadro de Datos a la psicologia del trabajo

Matrices básicas de análisis

Personas - Estímulos

Personas - Respuestas

Personas - Situaciones

Personas - Observadores

Estímulos - Respuestas

Estímulos - Situaciones

Estímulos - Observadores

Respuestas - Situaciones

Respuestas - Observadores

Situaciones - Observadores
Naturaleza factores obtenidos (ejemplos)

Clasificación actual de puestos de trabajo

Dimensiones de ejecución en los puestos Recursos humanos

Canales de mando y toma de decisiones

Análisis de tareas

Sistemas organizativos

Organización formal de la empresa

Eficacia y rendimiento organizativo

Eficacia y rendimiento según mandos

Los mandos en la empresa
Las posibilidades que esboza esta tabla son, transitoriamente, más sugerentes que efectivas. De momento no hay trabajos publicados en esta línea, prioritariamente porque los resultados son de interés interno para la propia empresa o entidad concernida. No obstante, muestra cómo esquemas de abordamiento peculiares a la Psicología Teórica pueden ser igualmente útiles para un trabajo sistemático en Psicología Aplicada. Es éste, pues, un modelo de análisis multivariado que resulta más ilustrativo que exhaustivo, ya que la magnitud de los datos que se incorporen dependerá del tema de estudio $y$, por tanto, la naturaleza de los factores será la correspondiente.

Aparte de este hecho, matrices como las aquí sugeridas facilitan toda una serie de análisis multivariados alternativos, tanto de predicción como de dimensiona- 
lización. Su aplicabilidad a la empresa es bastante obvia por cuanto se ciñe a una mera recogida de datos, sin ningún tipo de intervencionismo manipulativo ni experimental. Además, permiten operar con una amplia gama de variables en cada faceta, en un esquema muy afín al espontáneo de la realidad misma, que es multivariante.

\section{C) Análisis de predicción múltiple}

El buen funcionamiento de las empresas se fundamenta predominantemente en la previsión y en el manejo de información actualizada que reduzca costes, riesgos, márgenes de error o accidentes, etc. La razón de ser del psicólogo en un Departamento de Personal cuenta con una justificación palmaria: maximizar la predicción del rendimiento merced a una minimización de los errores y los costes. Algo similar puede decirse respecto a su incidencia en otras áreas.

A la hora de elegir una técnica multivariada predictiva es preciso clarificar tres aspectos: a) ¿El criterio de evaluación final es único o múltiple?

b) ¿El predictor se expresa a través de variables continuas o discontinuas?

c) ¿El criterio y el predictor están linealmente conectados o se dan sólo cierto tipo de interacciones?

Habitualmente la objeción c) suele obviarse asumiendo sin más una relación lineal (se simplifica tanto el diseño como el tratamiento de los datos, lo que representa un coste menor), dejándose para asuntos especialmente delicados la presunción de la interacción. Desde el punto de vista metodológico esto es un error, ya que la interacción es una evidencia funcional (por ejemplo, salarios-titulación académica-poder en la organización), por lo que la única alternativa consiste en linearizar la aproximación estadística y sugerir a continuación el tratamiento optativo.

La tabla 2 reseña sucintamente las técnicas disponibles en función de las alternativas viables en $a$ ) y en $b$ ).

TABLA 2

Clasificación de los métodos de predicción multivariada PREDICTORES MULTIPLES

\begin{tabular}{l|c|c}
\hline Criterio & Continua & Discontinua \\
\hline Unico & Regresión lineal múltiple & Función discriminante \\
\hline Múltiple & Correlación canónica & Análisis discriminante múltiple \\
\hline
\end{tabular}

La puesta en marcha de cada uno de estos análisis precisa, sin lugar a dudas, la utilización de programas adecuados que solamente pueden llevarse a término de un modo económico a través del ordenador. Aquí se expondrá, escuetamente, la lógica y limitaciones del procedimiento remitiéndose a los manuales para los detalles imprescindibles de su uso.

\section{Regresión múltiple lineal}

Ciertamente es la técnica más utilizada y conocida, ya que procura analizar la importancia o peso de cada variable independiente respecto a su contribución al valor de la variable dependiente. Se intenta, pues, descomponer la varianza $\left(\sigma^{2}\right)$ del criterio único en diversas partes 
atribuibles a la acción de las variables continuas que se utilizan como predictores. Dos son los resultados que se obtienen de este tratamiento estadístico:

a) El coeficiente de correlación múltiple ( $R$ ) que con un índice positivo predice la magnitud del criterio único en función de las variables predictoras, señalando en qué medida depende de ellas.

b) La ecuación de regresión múltiple con unos coeficientes beta $(\beta)$ (que se pueden transformar en pesos) permite predecir aditivamente el criterio ( $\left.\mathrm{x}^{\prime}\right)$ en función de las variables predictoras continuas $\left(X_{1}, X_{2} \ldots X_{n}\right)$, explicando así la dependencia causal entre aquélla y éstas. Expresada en puntuaciones típicas esta ecuación adopta la siguiente forma:

$$
z^{\prime}=\beta_{1} z_{1}+\beta_{2} z_{2}+\ldots \beta_{n} z_{n}
$$

El gran inconveniente de este procedimiento es que los pesos o los coeficientes beta van a oscilar considerablemente en función de la muestra utilizada, ya que opera mediante una optimización linearizada. Por ello, debe cuidarse bien el muestreo, ampliando el $\mathrm{N}$ o llevando a cabo validaciones cruzadas. Más detalles en torno a esta técnica pueden consultarse en C. Gil Muñoz (1972).

Un buen ejemplo aplicado de este procedimiento puede ser el verificar cómo el perfil de rasgos aptitudinales predice el buen rendimiento de una secretaria de dirección, habiendo evaluado a una muestra de éstas mediante una escala uniforme.

\section{Correlación canónica}

La correlación canónica viene a ser una ampliación de la regresión múltiple. Es el procedimiento adecuado cuando se cuenta con un conjunto de variables predictoras continuas que van a ser contrastadas con un criterio expresado a través de múltiples variables continuas. Por ejemplo, se pueden comparar los perfiles de rasgos aptitudinales, temperamentales y dinámicos (obtenidos durante un proceso de selección y de promoción) y ciertas anotaciones del expediente (como absentismo, tasa de errores o fallos, valoración de los jefes, etc.).

Partiendo, pues, de un conjunto de variables predictoras se intenta hallar una combinación lineal de todas ellas tal que al contrastar ésta con otra combinación lineal (correspondiente al conjunto de variables del criterio) se obtenga una correlación entre ambas que sea máxima. No es necesario que el conjunto de variables predictoras sea igual en número al de las del criterio. El procedimiento da lugar a una serie de combinaciones opcionales de las cuales sólo una maximiza la función, mientras que las otras tienden a mostrar resultados residuales. Dado que la distinción entre predictores y criterios es arbitraria (en realidad se trata de comparar dos conjuntos de variables linealmente combinadas), se obtendrán dos tipos de ponderaciones diferentes: una aplicable a las variables predictoras y otro a las variables del criterio. Expresándolo, la ecuación básica sería:

$p_{a} a+p_{b} b+\ldots p_{k} k=p_{m}^{\prime} m+p_{n}{ }_{n} n+\ldots p_{s}^{\prime} s$

Los distintos pesos ( $\mathrm{p}$ y p') serán mutuamente ortogonales y mostrarán una correlación máxima decreciente en función de la peculiar matriz de variacióncovariación.

Al igual que la regresión múltiple, la correlación canónica propende a maximizar las conexiones entre el primero y el segundo conjunto de variables, por lo que el resultado dependerá notablemente de la muestra utilizada, debiendo actuar con cautela a la hora de las generalizaciones y extrapolaciones. Pueden consultarse los artículos de J. Amón (1974), así como el de Cuadras y Sánchez Turet (1975), para una ampliación metodológica sobre el tema.

\section{La función discriminante}

Fue R. A. Fisher quien introdujo en los años treinta el uso de la función discriminante como una técnica estadística de clasificación. Se asemeja bastante a la 
regresiớn lineal múltiple. Un ejemplo típico de su aplicación puede consistir en dos muestras equiparables de sujetos con horarios de trabajo diurnos o nocturnos ( $\sin$ rotaciones); la primera muestra corresponde a sujetos con un serio accidente laboral en época reciente, mientras que los segundos no han tenido ninguno. Se cuenta con el perfil de rasgos pertinente a cada uno de estos individuos.

Aplicando la función discriminante se intenta hallar el vector ponderante que al ser aplicado a cualquier persona nueva o que aún no haya sido clasificada permita asignarle la categoría de accidentable o no con la menor probabilidad de error.

Los pesos beta utilizados para generar la combinación lineal ponderada se aplican a las puntuaciones medias predictoras de cada grupo. La puntuación individual prevista es contrastada con el centroide del grupo (que interviene «discriminando»), procediéndose a la oportuna clasificación estimada. Cuanto menor sea el coeficiente beta más afín será el individuo al grupo en que se le clasifica; cuanto mayores sean los coeficientes menor será la probabilidad de pertenencia al mismo.

Resulta evidente que la linearilidad de la relación predictor-criterio sustenta cualquier pronóstico realizado con este procedimiento, siendo particularmente ineficaz para los casos en que se da la interacción.

\section{El análisis discriminante múltiple}

A partir de los trabajos de Fisher, C. R. Rao desarrolló en los años cuarenta el análisis discriminante múltiple. En vez de calcular un solo vector de pesos halla uno para cada grupo que se incorpore al análisis. Puede servir el mismo ejemplo, pero tomando en consideración si el accidente es grave, leve o nulo. El procedimiento estadístico se asemeja bastante al análisis canónico: el número de variables supuestas es equivalente al número de categorías menos una; por ello mismo el número de ecuaciones resul- tante es igual al número de categorías del criterio (o del predictor, si es el menor) menos una. Asimismo, el primer conjunto de pesos o coeficientes beta representa la ecuación con mayor fuerza discriminativa, siendo las restantes decrecientemente residuales $\mathrm{e}$ independientes (lo cual puede utilizarse para ganar en precisión). Cualquier interpretación debe hacerse en función de los valores básicos diferenciales. La validación cruzada es imprescindible a la hora de iniciar cualquier extrapolación.

$\mathrm{Al}$ tener que bregar con problemas en los que se entrevea claramente que las relaciones no son lineales, es preciso recurrir a los modelos matemáticos ad boc disponibles; por no ser tan de uso común como los aquí apuntados se sugiere la consulta a textos o a profesionales especializados.

\section{D) Análisis dimensional o de factores}

Este tipo de análisis comparte un mismo sustrato: la covariación. Todos ellos persiguen, a su vez, un objetivo común: aislar y separar los focos de influencia y variabilidad subyacentes. De este modo se optima la utilización de los modelos lineales, toda vez que se tiene la certeza de estar trabajando con predictores no correlacionados entre sí. La tabla 3 resulta ilustrativa.

Otro de los usos habituales de este tipo de análisis es el de reducir el número de variables iniciales a un número menor que explique un alto porcentaje de la varianza total. Este procedimiento puede ser, por ejemplo, útil a la hora de intentar reducir a unos mínimos los datos significativos que deben ser incorporados a la ficha individual de personal (al introducir la mecanización en una empresa los ficheros deben condensarse a los mínimos funcionales). De igual manera estas técnicas permiten resolver objetivamente los problemas relativos a la agrupación o clasificación de plantillas o de puestos y funciones. Tanto el análisis factorial, como el análisis de componen- 
TABLA 3

Clasificaciones de los métodos de análisis dimensional multivariado

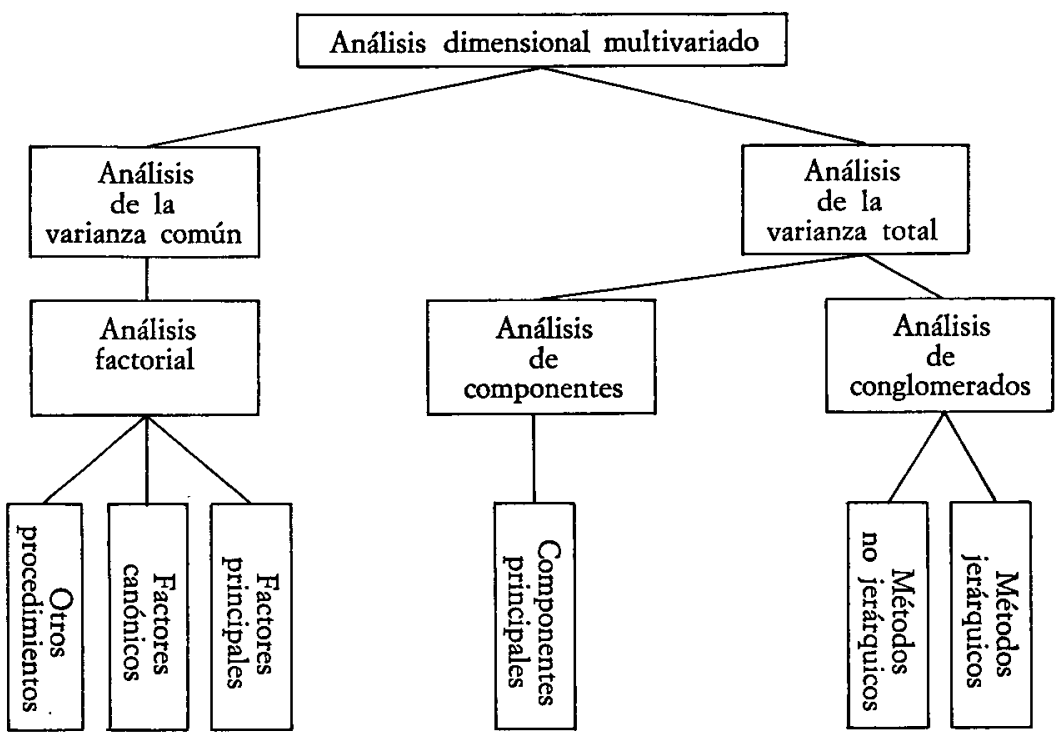

tes o el de conglomerados son virtualmente aplicables al desmadejamiento de las matrices aludidas en la tabla 1 , ya que permiten poner de relieve las estructuras subyacentes tanto en lo que concierne a los relativos como a los referentes.

\section{Análisis de componentes $y$ de factores}

Quizá uno de los aspectos que llamen la atención de la tabla 3 sea la separación que se hace entre los análisis por componentes y el análisis factorial propiamente dicho. Con harta frecuencia tiende a confundírselos en algunos artículos y trabajos, particularmente cuando se extraen los componentes principales en una matriz truncada (aplicando el criterio de Guttman: autovalores $\geqslant 1$ ). Las diferencias más notables están puestas de relieve en la tabla 4 .

Dado el ingente volumen de publicaciones psicológicas disponibles que han utilizado estas técnicas no será necesario hacer hincapié en ellas. En todo caso cabe remitir al lector a la reciente pu- blicación en español del texto más clásico en la materia, el de H. H. Harman.

Cuando el análisis sea más bien exploratorio suele ser conveniente iniciar una solución por componentes, mientras que cuando el análisis sea confirmatorio lo más adecuado puede ser una solución por factores principales (estando especialmente recomendado este procedimiento cuando la consistencia de las variables no esté predeterminada o se sospechen elevadas tasas de error instrumental).

Si se cuenta con un conjunto de variables predictoras y otro conjunto de variables criterio, lo adecuado será proceder a un análisis factorial canónico, procedimiento que deriva de los análisis de predicción múltiple ya comentados y que establece factores canónicamente correlacionados que aúnan ambos conjuntos de variables en la estructuración dimensional del ámbito objeto de estudio. Así, siguiendo con el ejemplo citado en la correlación canónica, podrá obtenerse factores que conjuguen los perfiles en los rasgos psicológicos de un lado y las anotaciones en el expediente laboral de otro. 
TABLA 4

Diferencias entre el método de componentes principales $y$ el de factores principales

\section{COMPONENTES PRINCIPALES}

1. Los componentes principales intentan condensar la varianza total.

2. Un número dado de variables se transforma lineal y ortogonalmente en un número equivalente de nuevas variables con la peculiaridad de no estar correlacionadas.

3. El orden de aparición de los componentes está en relación directa con la varianza explicada.

4. La transformación tiene lugar una vez que se han obtenido los autovalores y vectores pertinentes.

5. Los componentes habidos son, pues, funciones lineales de las variables originales.

6. Para el abordamiento de las matrices es conveniente que todas las variables se midan en las mismas unidades. Así, la varianza total será igual a $n$, y sus componentes reales y positivos.

\section{FACTORES PRINCIPALES}

1. Los factores principales intentan condensar la varianza común.

2. Se intenta representar sucintamente, merced a los factores comunes que se obtengan, el máximo viable de la varianza correlacional entre las variables originarias.

3. El orden de aparición de los factores no depende directamente de la porción de la varianza explicada.

4. La extracción tiene lugar por pasos sucesivos una vez eliminada la correlación parcial atribuible a los factores.

5. Los factores que se aceptan son exclusivamente los comunes, desechándose los residuales por específicos. La función no es exactamente lineal respecto a las variables originarias.

6. La atención del análisis queda centrada en la matriz de correlaciones, con independencia de las unidades de medida. Pueden surgir autovalores irreales y negativos que son residuales.
Estos factores tendrán la peculiaridad de no estar rotados (lo cual dificulta la interpretación), pero, eso sí, ser mutuamente independientes.

\section{Análisis de conglomerados}

Esta técnica ha sido pensada para proceder a clasificar objetos o personas reuniéndolos en grupos homogéneos. A nivel global cabe distinguir dos enfoques diferenciados: aquel que agrupa y reagrupa los conglomerados hasta constituir una jerarquía o árbol, y aquel que se limita a la mera clasificación, haciendo hincapié en maximizar la homogeneidad de los grupos. La oportunidad de un modelo u otro dependerá del problema que se aborde. Si se quiere contrastar el organigrama formal vigente con el organigrama no formal latente y funcional en una organización clásica, lo más obvio será recabar una solución jerárquica. $\mathrm{Si}$, en cambio, se está llevando a cabo una valoración de puestos con vistas a trazar un mapa salarial más ajustado a las funciones y responsabilidades, ambas opciones son viables, aunque está especialmente recomendada la no-jerárquica cuando los puestos objeto de estudio alcancen solamente un cierto nivel de la organización. Estos últimos son igualmente los idóneos cuando se trata de catalogar clientes en estudios de imagen o de control de campo.

Aparte de la mera clasificación, los análisis de conglomerados pueden ser oportunos para trabajos de «ajuste de modélos o sectores», predicciones a partir de grupos de referencia, comprobación de hipótesis en grupos ya sesgados en la realidad, exploración de datos, relanzamiento de nuevas hipótesis en estudios de campo, homogeneización de ficheros a partir de las semejanzas, etc.

Dos son las limitaciones más notables de este tratamiento: de un lado, los grupos o clases que se extraigan del análisis dependerá en notable medida del criterio estadístico adoptado para determinar la similaridad o la homogeneidad de sus componentes (correlaciones, dis- 
tancias euclidianas, etc.), por lo que puede ser conveniente tantear diversas soluciones, con vistas a obviar el artificio estadístico, eligiendo finalmente los conglomerados reincidentes; por otra parte, cabe afirmar algo similar respecto a la dependencia de las «peculiaridades muestrales» en las clasificaciones finales. Esto puede resultar una ventaja para quien se ciñe al conjunto de personas objeto de estudio, mientras que puede ser un inconveniente para quien desea plantear generalizaciones o extrapolaciones.

Una de las peculiaridades comunes a todos los enfoques de tipo multivariado reseñados hasta aquí es la siguiente: no existe una solución final única. Todas estas técnicas, basadas en algoritmos matemáticos de índole bastante afín, se resuelven a través de complejas ecuaciones que siempre desembocan y entrañan soluciones finales equivalentes y equipotentes desde el punto de vista estadístico. Esto no quiere decir arbitrariedad, sino flexibilidad para que el psicólogo del trabajo pueda manejar las diversas opciones con vistas a elegir aquella que más se adapte a los objetivos del diseño, al rendimiento o logro planteado, al criterio psicológico más pertinente, etc. Utilizando un símil, «lo asombroso no es que su reloj y el mío no marquen la misma hora, sino que Ud. y yo logremos ser puntuales si nos citamos para tomar el té juntos en el polo»; los ajustes son de fracción, no de tiempo.

\section{PREDICCION CENTRADA EN LA PERSONALIDAD}

Cuando se lleva a cabo una revisión de las publicaciones en torno a la predicción y el rendimiento a partir de pruebas psicológicas, se constata el siguiente hecho: el énfasis parece situarse en los rasgos aptitudinales (intelectuales, sensoriales o motrices); seguidamente suelen tomarse en consideración los rasgos temperamentales y sólo en muy contadas ocasiones suelen incorporarse los rasgos dinámicos (actitudes, motivación, sentimientos, instintos o ergios).

Es preciso reconocer que esta actuación ha venido dictada por los paulatinos avances de la Psicología Diferencial en los ámbitos reseñados. Actualmente, sin embargo, el énfasis viene a situarse en la personalidad en cuanto suprasistema individual que facilita la interacción con el medio (Prieto, 1980). Se recupera, pues, el significado lato de personalidad entendiéndose por tal «la configuración - tanto dinámica como estable - de los repertorios, estilos y predisposiciones comportamentales que, de un modo innato o bien adquirido, desarrollan las personas humanas en su interacción con la realidad y en función de las cuales es posible establecer un pronóstico respecto a la conducta vaticinable en un contexto determinado». Esta configuración se decanta y pone de evidencia a través de una «organización estructurada de sistemas, sub-sistemas y rasgos que vehiculizan, transforman e integran la información».

Este nuevo enfoque permite sincronizar los hallazgos taxonómicos de los psicólogos multivariados con las intuiciones y derivaciones de los psicólogos afines a la teoría general de sistemas, así como con los esquemas explicativos de los psicólogos cognitivos. No se trata de entender los rasgos como meros constructos teóricos estáticos, sino como focos de influencia y determinación, como repertorios estratégicos comportamentales, como productos del aprendizaje. De hecho, en esta nueva perspectiva, el tema del aprendizaje humano (por el gran impacto que en él tiene el recurso sistemático a símbolos y cargas emotivas) es reconsiderado a la luz de los sucesivos cambios que acaecen en la personalidad en cuanto globalidad de rasgos. Surge así la teoría estructurada del aprendizaje que aborda éste no como mero proceso reactivo, sino, fundamentalmente, como proceso dinámico de asimilación y cambio en la personalidad involucrada (Cattell, 1980; Royce y Powell, 1980).

En esta nueva tesitura quedan, pues, virtualmente desfasadas buena parte de 
las estrategias en uso. De hecho, esto implica que cada vez se incorporen en la predicción los distintos sub-perfiles de los individuos.

\section{Ajuste de perfiles}

Las distintas pruebas factoriales disponibles apuntan a la identificación de una serie de constructos teóricos conocidos virtualmente como rasgos fundamentales en las esferas aptitudinal, temperamental y dinámica. Son varios los usos que se pueden hacer de los perfiles obtenidos por un individuo. Desde el más común y habitual, que se reduce a la lectura de las anotaciones correspondientes del manual y su interpretación generosa, hasta el más estricto y cuidadoso que intenta avanzar en la predicción merced a procedimientos más detallados y objetivos. Este último procedimiento intenta hallar las semejanzas entre sucesivos perfiles sometidos a contraste.

$\mathrm{La}$ asunción del ajuste de perfiles en psicología del trabajo implica que se sobreentiende que los perfiles obtenidos (tanto a nivel individual como de grupo) no son ni espúreos ni producto del azar. Reflejan, a través de las sucesivas puntuaciones, las peculiaridades inherentes al individuo o grupo objeto de estudio. Si, por ejemplo, se está estudiando el perfil de un grupo de enfermeras (Prieto, 1977), no se está entendiendo que éstas sean las idóneas o ideales; más bien se está asumiendo que el perfil del grupo que se identifica y trabaja en su profesión recogerá características propias y necesarias para el cotidiano desenvolvimiento laboral. Con el análisis de perfiles se está afirmando simplemente que cada grupo profesional porta su sello de marca.

Para llevar a cabo los ajustes de perfiles son varios los procedimientos estadísticos disponibles, compartiendo casi todos ellos el principio conocido como $\mathrm{D}^{2}$ de Mahalanobis. Un índice desarro llado a partir de dicho principio es el coeficiente de similaridad de patrones
( $\left.r_{p}\right)$ planteado por Cattell (1949), completado por Horn (1961) y que permite realizar las siguientes comparaciones:

- Perfil individual con perfil individual.

- Perfil individual con perfil de grupo.

- Perfil de grupo con perfil de grupo.

Su formulación básica es la siguiente:

$$
r_{p}=\frac{E_{k}-\sum_{1}^{k} d^{2}}{E_{k}+\sum_{1}^{k} d^{2}}
$$

donde $E_{k}$ viene a ser la suma esperada de los cuadrados de las diferencias a lo largo de $\mathrm{k}$ elementos (expresándose normalmente mediante la mediana del $\chi^{2}$ para k grados de libertad); $\sum_{1}^{k} d^{2}$ viene a ser la suma real de los cuadrados de las diferencias en puntuaciones típicas de los dos perfiles a lo largo de los $\mathrm{k}$ elementos. Puede consultarse en N. Seisdedos (1981) ejemplos desarrollados con cada una de las tres opciones.

El planteamiento subyacente a este ajuste de perfiles radica en la constatación de que no siempre las puntuaciones más extremas en un rasgo son adecuadas para un buen desempeño habitual. Hay rasgos que se hacen ver (o se echan en falta) con una tasa dada (pero no en exceso o déficit) para el buen desenvolvimiento; normalmente esta peculiaridad se recalca a través del modo de conjugarse el perfil o los perfiles. El interrogante subsiguiente es si los perfiles de los actuales profesionales son los pertinentes para los nuevos problemas y retos que la sociedad competitiva plantea a la empresa o al trabajador. La elección entra de lleno tanto en los trabajos de investigación como en los criterios vigentes de política de personal, por lo que se teseña aquí el procedimiento sin entrar en el fondo de la cuestión. 


\section{Ecuación de especificación}

Este procedimiento comparte buena parte de la lógica referida al hablar de la regresión múltiple lineal; de hecho, la ecuación final es muy similar, operando aquélla con variables y ésta con factores.

A través de la ecuación de especificación se pretende estimar cuáles son las aportaciones de los factores que optimizan la eficacia o el rendimiento. Esto se traducirá en unos pesos o coeficientes beta que ponderarán la contribución maximizadora de cada rasgo, convirtiéndose en multiplicadores fijos de las puntuaciones que los individuos hayan mostrado en las sucesivas escalas de los diferentes perfiles.

Cuando los perfiles están trazados mediante la información suministrada por los componentes principales, la ecuación básica será:

$$
\begin{aligned}
a_{j}= & b_{j 1} F_{1}+b_{j 2} F_{2}+\ldots+b_{j n} F_{n} \\
& \text { donde } j=1,2, \ldots n
\end{aligned}
$$

mientras que si se ha basado en los factores principales, la ecuación será:

$$
\begin{gathered}
a_{j}=b_{j 1} F_{1}+b_{j 2} F_{2}+\ldots+b_{j m} F_{m}+b_{j} U_{j} \\
\text { donde } j=1,2, \ldots, n
\end{gathered}
$$

haciendo intervenir $m$ factores comunes y un factor único.

Quizá estas ecuaciones, novedosas pata buena parte de los lectores, planteen un interrogante común: ¿qué tienen que ver con el paradigma conductual en que se mueve la psicología académica? No resulta difícil retrotraer este aspecto. En el paradigma básico, ésta es la ecuación que sirve de referencia a los psicólogos de la personalidad:

$$
\mathrm{R}=\mathrm{f}(\mathrm{O} \cdot \mathrm{S})
$$

Aquí se está explicitando claramente que toda respuesta conductual del sujeto (R) puede recapitularse en términos de una - función $(\mathrm{f})$ que involucra las peculiaridades del organismo $(\mathrm{O})$ y las características de la situación estimular (S).

En términos multivariados este para- digma halla su expresión gráfica y expresiva a través de la ecuación de especificación misma:

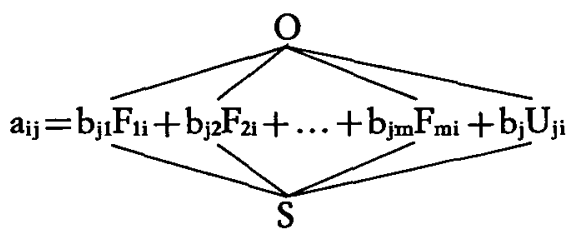

Aquí se evidencia que la eficacia en la actuación de un individuo en un contexto concreto $\left(a_{i j}\right)$ logra su expresión a través de unos vectores o coeficientes beta ambientales $\left(b_{j}\right)$ peculiares para cada factor $\left(F_{m i}\right)$ en cuanto expresión vectorial de la dotación fenotípica de cada individuo en el rasgo en cuestión. El modelo es lineal y aditivo e incorpora así mismo lo que de único tiene la situación $\left(\mathrm{b}_{\mathrm{j}} \mathrm{U}_{\mathrm{ji}}\right)$ para ese individuo. De esta guisa se enfatiza el hecho (normalmente pasado por alto por los críticos) de que el modelo multifactorial está centrado en la persona, pero involucrando en la misma la incidencia del medio en que se desenvuelve. Incluso a nivel teórico la eficacia pronosticada puede desdoblarse en cinco subíndices que hacen referencia a cada uno de los ejes que constituyen el cuadro de datos $(\mathrm{i}=$ individuo-personas, $\mathrm{h}=$ estímulo debidamente focalizado y percibido, $\mathrm{j}=$ respuesta ejecutoria demandada, $\mathrm{k}=$ contexto de la situación de recogida de datos, $o=o b s e r-$ vadores) que puede cobrar su forma definitiva en los siguientes términos:

\section{a hijko}

El desarrollo aplicado de estas ecuaciones es aún un tema pendiente, pero el hecho evidente es que este tipo de análisis está centrado en la persona imbuida en su situación y no un mero análisis estadístico de las respuestas dadas a los tests.

Volviendo al tema de origen, es posible recoger las distintas aportaciones de los rasgos aptitudinales (A), temperamentales $(T)$ y dinámicos (D) en una ecuación de especificación totalizadora que asumiría, sucintamente, este formato: 


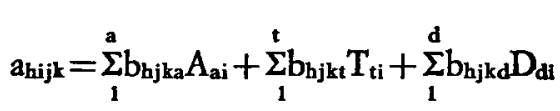

+lo específico o único.

En este tipo de modelos de amplio espectro $y$ alcance se hallan empeñados, desde hace años, varios centros de investigación cuyas personalidades más destacadas son R. B. Cattell y J. R. Royce.

La figura 1 ilustra con nitidez los nexos inductivo-deductivos inherentes a la Teoría Multidimensional de la personalidad. Los factores son extraídos inductivamente del cúmulo de variables de la realidad psicológica. Puesto que son relevantes y estadísticamente representativos, son recuperados y utilizados de nuevo a la hora de situar a cualquier individuo, así como al llevar a cabo deductivamente una predicción que apunte a hechos reales. Son, pues, dimensiones teórico-aplicadas que remiten y reinciden en el contexto psicológico para el que son pertinentes. En este ciclo la vertiente inductiva es la más poderosa y contrastada; la deductiva, por su sistematización reciente, precisa aún verificaciones y controles rigurosos, así como la incorporación de nuevas técnicas y procedimientos más estrictos (las críticas desde los modelos situacionistas se han centrado, precisamente, en la debilidad de esta vertiente; pero, por su parte, han sido incapaces de lograr extrapolaciones inter-situacionales).

\section{FIGURA 1}

El ciclo predictivo centrado en la personalidad (D. C. Thompson, 1977)

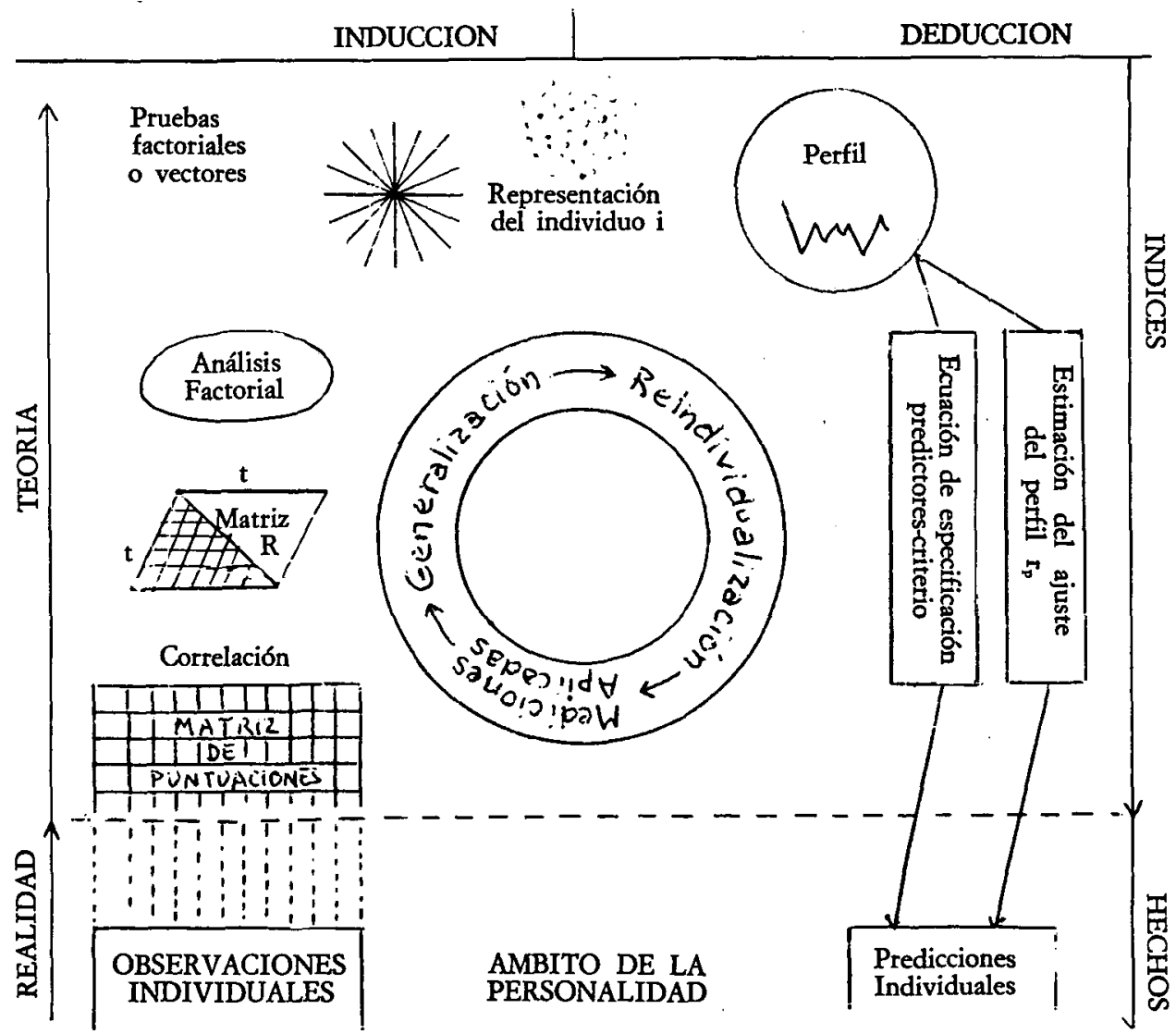


Ahora bien, incorporando tantos elementos de información predictiva ¿se logra realmente mejorar el pronóstico del rendimiento? La respuesta parece ser, en principio, afirmativa. No existen, por ahora, datos (provenientes del área de la psicología del trabajo) publicados o accesibles, pero, partiendo de los precedentes de Cattell y Butcher (1968) que se incluyen en la tabla 5 , es posible asentir ante dicho interrogante.

TABLA 5

Rendimiento escolar y nota escolar promedio en bacbilleres en función del perfil en los rasgos

\begin{tabular}{llc}
\hline & $\begin{array}{c}\text { Correlación } \\
\text { con el } \\
\text { criterio }\end{array}$ & $\begin{array}{c}\% \text { de la varianza } \\
\text { del criterio } \\
\text { predicha }\end{array}$ \\
\hline 1. Aptitudes: Inteligencia fluida & 0,45 & 20,3 \\
2. Temperamento (HSPQ-13 factores) & 0,43 & 18,5 \\
3. Motivación (SMAT-15 factores) & 0,40 & 16,0 \\
4. Aptitudes y Temperamento & $0,79(1)$ & 62,4 \\
5. Temperamento y Motivación & 0,53 & 28,1 \\
6. Aptitudes, Temperamento y Motivación & 0,78 & 60,1 \\
\hline
\end{tabular}

(1) Esta muestra es distinta de las restantes.

Los índices que se recogen en esta tabla no provienen de una aplicación directa de la ecuación de especificación, sino de una estimación derivada a partir de los coeficientes beta habidos. En los manuales de casi todos los tests desarrollados por Cattell y colaboradores pueden encontrarse los resultados de numerosas investigaciones con ecuaciones de especificación y los pesos a utilizar en regresiones factoriales respecto a variados criterios de eficacia en la empresa.

La tesis doctoral de R. Martínez (1977) suministra información pertinente respecto a la ganancia predictiva al incorporar factores de cada ámbito en la predicción del criterio, en su caso el rendimiento matemático.

A la luz de cuanto se ha señalado hasta aquí puede afirmarse que los psicólogos del trabajo y los psicólogos académicos están ya utilizando un lenguaje y esquema de trabajo que comparte soluciones ejemplares al paradigma común:

1. De la utilización de tests y variables inconexas se está pasando a una exploración predictiva centrada en la personalidad, sirviéndose de pruebas multifactoriales que ponen de relieve rasgos y perfiles independientes pero coherentes entre sí.

2. Frente a las interpretaciones subjetivas se está poniendo el énfasis en instrumentos objetivos de evaluación, que se sitúan en un nivel prioritariamente descriptivo de la conducta, e identifican constructos teóricos verificables con independencia de muestras y de instrumentos.

3. Desde un uso ingenuo de la estadística descriptiva se está avanzando pausadamente hacia un dominio de la estadística multivariada entendida como medio que facilita la clarificación de estructuras, clasificaciones y predicciones probabilísticas de función maximizadora.

4. Desde unos esquemas de investigación basados en la manipulación experimental se está pasando a trabajos de campo en que las diferencias humanas, convertidas en objeto de estudio, permiten una comprensión más cabal de las estructuras y procesos subyacentes. 
5. Frente a unos resultados parcializados, debido a los sesgos de las muestras e instrumentos, se está logrando la incorporación y ampliación sucesiva de los hallazgos merced a la recuperación de diseños y estrategias aplicables a un conjunto abierto de sujetos y de variables. Se tiende a minimizar así el error muestral y el instrumental.

Estas son, pues, las aportaciones más destacadas de la confluencia del enfoque psicométrico multivariado y una psicología de la personalidad de raigambre multidimensional.

\section{CRITERIO Y VALIDEZ EN PSICOLOGIA DEL TRABAJO}

A lo largo de estas páginas se ha hecho mención al quehacer predictivo en función de un criterio final de contraste. Viene a ser una especie de talón de Aquiles en el cual no parece aún haber acuerdo entre los psicólogos-profesionales y los psicólogos-académicos. Aquéllos prefieren expresarse en términos de criterio y éstos en términos de validez a la hora de controlar el nivel de eficacia alcanzada.

Si se consulta el diccionario se constata que «criterio» resulta ser «la norma, juicio o discernimiento para conocer la verdad», mientras que «validez» connota «la estimación, creída o recibida, del conocimiento de una verdad». En ambos casos tanto la validez como el criterio deben traducirse en una medición o sistema de evaluación que sea lo suficientemente dúctil y sensible como para establecer una diferenciación entre individuos o grupos.

\section{Criterio}

Han sido tan frecuentes y ávidos los esfuerzos de los psicólogos del trabajo en torno a la decantación objetiva del criterio que casi puede hablarse de un «paradigma del criterio». A falta de un marco teórico coherente, el criterio se ha convertido en la piedra de toque de cualquier innovación, enfoque o cambio de perspectiva intentado. En alguna medida puede hablarse de «obsesión por los resultados» entre los psicólogos industriales frente a la parsimonia investigadora de los académicos.

Tres son las dimensiones que parecen caracterizar el abordamiento clásico del criterio:

1. El eje temporal, ya que toda ejecución tiene lugar con una proximidad o distancia en el tiempo y a su vez cualquier norma útil mantiene solo una vigencia transitoria; cualquier predicción estará así condicionada por los plazos - corto o largo- involucrados.

2. El eje real, que puede oscilar entre el rendimiento específico y el final (es distinto predecir el éxito de un piloto para el vuelo o para el combate).

3. El eje de la adecuación a los objetivos inmediatos (centrados en los resultados) o a los mediatos (efectividad por rebote) de las organizaciones o los individuos en la sociedad.

Esta constatación, que ha sido más bien paulatina, ha forzado a los psicólogos del trabajo a evitar regresiones hacia «el mejor criterio» (expresado a través de una variable óptima); normalmente la elección se sitúa entre el «criterio compuesto» (combinación lineal ponderada de diversos tipos de evaluaciones), el «criterio múltiple» (en el que cada evaluación se considera pertinente y suficiente, pues a su través se expresan los componentes estáticos, dinámicos o individuales de los rendimientos (Ghiselli, 1956)) o el «criterio general» (que se basa en la efectividad en la política directiva y en la explicitación de los componentes y dinamismos que la facilitan (Campbell y otros, 1970)).

P. C. Smith (1976) plantea, incluso, el tema del rendimiento a unos niveles decididamente empíricos; distingue entre «criterios duros» (retrasos, absentis- 
mo, accidentes, ventas, producción, rotación y bajas, promociones, nivel profesional o salarios) y «criterios blandos» (errores comunes, escalas de valoración de méritos o entrenamiento de supervisores y calificadores, y todos éstos cuentan con un elevado riesgo de contaminación o desvirtuación).

Este panorama tan profuso, sucintamente esbozado, ha hecho caer en la cuenta de la necesidad de lograr identificar «constructos de criterios» (James, 1973), siempre que se recurra a mediciones contaminadas o escalas de evaluación múltiple, ya que son muy contadas las ocasiones en que se cuenta con criterios objetivos. En definitiva, se está apuntando a lo que los psicólogos académicos mencionan como 'validez de constructo' y que se configuraría mediante todo tipo de mediciones relativas a tiempo, complejidad, niveles de adecuación, resultados, comportamiento, implicaciones organizacionales, medidas objetivas del rendimiento en los puestos, clima laboral y medio de trabajo, etc. En pocas palabras, se está concluyendo que el criterio en cuanto norma es muy difícil de objetivar, por lo que la alternativa pendiente es proceder a una estimación del resultado, es decir, un replanteamiento de la validez.

\section{Validez}

Los psicólogos académicos han desarrollado el concepto de validez con la mira puesta en el control de qué es lo que mide una prueba y cómo lo mide. Desde un punto de vista clásico (APA, 1966) son tres las categorías principales: validez de contenido, validez empírica y validez estructural. Fue éste un enfoque excesivamente centrado en los esquemas psicométricos vigentes y predominantes en aquella época, con algunas limitaciones en cuanto a su aplicabilidad a la esfera educativa. Los psicólogos del trabajo fueron más bien reacios a su adopción.

Por aquella misma época, Cattell (1964) y Cattell y Butcher (1968) pro- pusieron un esquema diferente de abordamiento de la validez, teniendo en mente precisamente sus implicaciones en la predicción del rendimiento y la eficacia en psicología aplicada. Esbozaron tres parámetros dicotomizados que, tomados en consideración, cercioran en qué forma un predictor atina en el objetivo que pretende medir.

La primera de estas dimensiones implicaría el grado de abstracción inherente al criterio de referencia: oscila desde el polo de lo concreto (predicción de la destreza en el manejo de una excavadora) al de lo conceptual (predicción de una valoración global «es un buen trabajador»). Sin lugar a dudas, los psicólogos del trabajo tienen que atender habitualmente a pronósticos concretos, obviando las derivaciones de tipo conceptal (la «validez de constructo» sería una de sus manifestaciones). Ahora bien, al utilizar análisis factoriales de tipo canónico, se pueden decantar estructuralmente los nexos predictores-criterios en lo que concierne a la vigencia de esta dimensión si entre los criterios se conjugan aspectos concretos y aspectos conceptuales (que no suelen ir $\tan a$ desmano).

La segunda estriba en el grado de naturalidad de los elementos de información que dan pie a la inferencia: oscila desde un polo centrado en lo natural y usual (predicción en función del número de errores cometidos o evitados, volumen de productos vendidos o años de permanencia en la empresa) hasta el que apunta a lo artificial (predicción basada en el coste hombre-puesto, productividad horatrabajada, carga social de los nuevos empleados o de los que causan baja o sobre todo coincidencias con otros tests o escalas de uso interno de la empresa). Los psicólogos del trabajo se han desenvuelto en ambos polos de esta dimensión, constatando reincidentemente lo espúreo de poner exclusivamente el énfasis en una de las dos vertientes.

La tercera se define por el grado de pertinencia que oscila entre un polo que busca la conexión directa (correlación en- 
tre razonamiento numérico $y$ un buen desempeño en tareas contables) de un lado y la indirecta o circunstancial (los matemáticos brillantes deben destacar en razonamiento abstracto y en numérico) de otro. La gran mayoría de las predicciones se han centrado, habitualmente, en la identificación de los aspectos directamente involucrados; últimamente, a través de las ecuaciones de especificación - los ajustes de perfiles, puede verificarse en qué medida los rasgos fundamentales de la personalidad resultan coherentes (a través de las puntuaciones - de los coeficientes beta que cambian y se confirman según las peculiaridades de las muestras); con ella parece reafirmarse la oportunidad de esta validación indirecta (que demuestra una convergencia extrínseca al predictor y al criterio: la de las personas que destacan en ambos). Lo valioso de esta validez circunstancial o indirecta radica en que se muestra solvente con independencia de los procedimientos estadísticos o experimentales utilizados en el diseño. Así, Blanco Cotaño (1978) al estudiar los perfiles de personalidad de auxiliares administrativos con buenos y malos informes comprobó divergencias comprensibles en determinados rasgos y a su vez comprobó cómo el perfil de los auxiliares «integrados» propendía a asemejarse al de los mandos. Es éste un ejemplo nítido de validez indirecta: los cuestionarios multifactoriales usados fueron lo suficientemente dúctiles en la identificación de los rasgos como para poner sobre el tapete los cambios inherentes a la asimilación burocrática.

Son ocho las combinaciones posibles entre los tipos de validez teóricamente viables, según se recoge en la figura 2; sin embargo, no todas son de igual utilidad en psicología. Así, las que se estiman con mayor frecuencia son la validez conceptual directa y la conceptual circunstancial cuando se recurre a pruebas multifactoriales como predictores $y$, en menor grado, la conceptual natural y la conceptual artificial. No obstante, el psicólo del trabajo tiene que echar mano, a menudo, de cualquiera de ellas; por ejemplo, de la validez concreta directa (cuando se utiliza un juego de anillas para predecir la destreza como clasificador de piezas).

FIGURA 2

Dimensiones de la validez y posibles variaciones a la bora de obtener coeficientes de validez (Cattell, 1973)

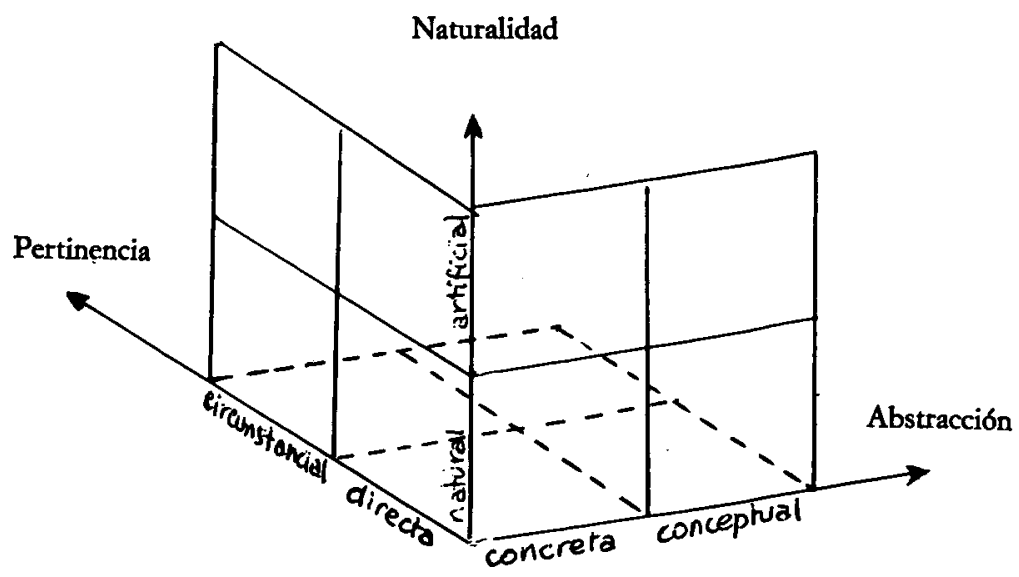


Merece la pena subrayar este esquema tridimensional por cuanto, con cierta asiduidad, tiende a rechazarse sin más un predictor psicológico dado porque no ha sido lo suficientemente sensible en la estimación de una regresión específica (absentismo, desfalco, excesiva conflictividad, etc.): nada más infundado. Se pueden dejar de lado esas pruebas por no inspirar suficiente confianza; pero lo más pertinente debería consistir en verificar qué tipo de validez se le exigió al predictor y qué otros tipos de validez demostró (y no se tomó en consideración). Dado que la predicción toma cuerpo en torno a la estructura interna de la personalidad - tomándola como centro de atención-, puede y suele seguir mostrando su vigencia en otras áreas más amplias y naturales (por ejemplo, en la sintalidad de los distintos subgrupos que constituyen la plantilla de personal), siendo necesario utilizar pruebas más homogéneas y minuciosas para pronósticos de tipo concreto directo o concreto natural.

Si se contrastan estas tres dimensiones de la validez y las tres dimensiones de los criterios pueden comprobarse notables solapamientos (especialmente entre el eje real y el grado de abstracción, entre el eje adecuación y el grado de pertinencia y, finalmente, entre el eje temporal y el grado de naturalidad), en orden decreciente. Todo parece, pues, apuntar a una progresiva conjunción de estrategias y diseños entre los psicólogos profesionales y los académicos, merced a una simbiosis de modelos y conceptos que difuminan lindes.

Hasta aquí se han venido exponiendo, escuetamente, una serie de técnicas y tácticas que están al alcance del psicólogo del trabajo cuando tiene que ocuparse de la predicción del rendimiento de otros profesionales. Ahora bien, ¿cuáles son los parámetros básicos que definen la eficacia del propio psicólogo del trabajo? Subjetivamente puede entender que su función consiste en investigar, desarrollar y aplicar técnicas psicológicas al ámbito de la humanización y satisfacción en el trabajo. Sin embargo, la justificación de su tarea viene pautada desde otras ópticas más objetivas:

1. Eficiencia, maximizando resultados consistentes en unos mínimos de tiempo disponibles.

2. Economía, contribuyendo a la reducción de costes, tanto humanos como organizacionales y financieros.

3. Transferibilidad, exigiéndole la suficiente amplitud de miras y de formación como para afrontar con presteza retos y exigencias nuevas.

4. Utilidad, estando obligado a convencer, con la labilidad del sofista en ocasiones, del abanico de recursos de que dispone (al margen de dudas) mediante una rapidez y flexibilidad de clausura que le permita subsistir en su identidad a través del quiebro interdisciplinario.

Son estos los criterios que enmarcan, habitualmente, al psicólogo del trabajo y que no agobian activamente al psicólogo académico. No está de sobra recogerlos aquí, un poco al margen. Su impacto e incidencia no suele ser objeto de predicción ni de estudio.

\section{PSICOLOGIA DIFERENCIAL Y PSICOLOGIA DE LAS ORGANIZACIONES}

Evidentemente los modelos expuestos hasta aquí, particularmente en lo que concierne a la predicción y al criterio en torno al rendimiento, enfatizan tres de los ejes del cuadro de datos básicos: personas, estímulos y respuestas. Ahora bien, ¿cómo se está logrando integrar las situaciones y los observadores en este tipo de trabajos?

Las empresas consultoras suelen planear sus intervenciones en las industrias partiendo de esquemas de análisis cuyo énfasis radica en la peculiaridad de las situaciones internas. Esto ha traído como fruto una amplia gama de hallazgos y 
constataciones a las que genéricamente se las ha agrupado bajo el epígrafe «psicología de las organizaciones». Sus estrategias suelen provenir de la psicología social aplicada, por lo que sus objetivos de abordamiento prioritario se ciñen a la organización empresarial misma, a los procesos de cambio, al rendimiento en los grupos, al ambiente social y motivación laboral, etc. Se ocupan prioritariamente de la comprensión de las fuerzas en interacción y de la obtención de unos resultados a corto plazo, por lo que los esfuerzos de sistematización son escasos (aunque por contrapartida son numerosos los textos de divulgación de técnicas e intuiciones funcionales semi-estructuradas).

Desde hace algunos años se está vislumbrando la posibilidad de abordar sistemáticamente las organizaciones como una variedad más del ambiente psicosociológico (y cuyo entramado parece conectar de un lado con la dirección organizativa y de otro con las redes operativas de la informática en el seno de la empresa). Sin duda, la organización es un contexto que debe ser incorporado al esquema predicción-critèrio, toda vez que modula palpablemente cualquier rendimiento o eficacia que se pretenda evaluar. En la organización ocurren cambios y tensiones que afectan a la actuación de las personas; estos cambios no se producen al azar ni sus efectos se anulan mutuamente; mas bien se concatenan generando un progreso o un declive; sus efectos son tangibles en todos y cada uno de los niveles humanos que configuran el perfil productivo de la empresa. Es éste, quizá, el verdadero punto muerto de un enfoque exclusivamente diferencial de la psicología del trabajo. La organización promociona habitualmente a las personas no tanto por sus perfiles y predisposiciones, sino por su integración eficaz en el sistema interno, reforzando sólo la adecuación a los logros y objetivos implícitos o explícitos. «No triunfan los que valen, sino los que pueden.»

La salida a esta situación de «impasse» puede ser doble:
1. Considerar los moldes de trabajo consuetudinarios y reaplicarlos concienzudamente hasta lograr una especie de mapa diferencial de la organización; los ordenadores pueden facilitar la labor, mediante programas harto sofisticados de simulación, teoría de juegos, análisis multivariados, etc.

2. Tomarse un respiro en el abordamiento exclusivo de problemas aplicados e iniciar un proceso de elaboración teórica sistemática a partir de los interrogantes y temas candentes para los cuales no se cuenta aún con metodologías ni estrategias pertinentes.

Hay autores y centros de investigación que están pulsando ambas salidas. En la primera línea están trabajando, por ejemplo, en la Universidad de Minnesota, dando paso a una serie de publicaciones que se ocupan de los temas clásicos a la luz de una reinterpretación de los patrones dominantes en cada organización (Dunnette, 1976). En la segunda línea están avanzando una serie de investigadores que se reagrupan en torno a las Universidades de Harvard, Yale y California. Uno de éstos, C. Argyris (1976), resenaba y comentaba los cinco interrogantes que los psicólogos del trabajo deben resolver y afrontar para asegurar un mínimo de eficacia y continuidad profesional. Merece la pena recoger su escueto enunciado:

1. ¿De qué manera los individuos y las organizaciones logran reducir las diferencias individuales respecto a las variables predictoras, moduladoras $y$ criterios?

2. ¿De qué manera pueden diseñarse las organizaciones de suerte que disminuya la supresión disfuncional de las diferencias individuales en las capacidades y desempeños humanos?

3. ¿De qué forma puede diseñarse la investigación tecnológica de manera que no demande inintencionadamente la aceptación del status quo en el universo?

4. ¿Cómo puede lograrse un conoci- 
miento sistemático que propicie la competencia de los sistemas objeto de estudio?

5. ¿Cómo pueden integrarse efectivamente la psicología industrial y la psicología de las organizaciones?

(C. ArgYrIs: «Problems and New Directions for Industrial Psychology», en M. D. Dunnette: Handbook of Industrial and Organizational Psychology, Chicago, Rand McNally, 1976, págs. 168-181.)

Como se desprende de la lectura de estas cuestiones, los objetivos perseguidos distan notoriamente de los desarrollados en estas páginas. El objeto de estudio es la optimización tanto del diseño como del rendimiento global de la organización, tarea en la cual debe confluirse con las aportaciones pertinentes de otras profesiones. De hecho, este tipo de interrogantes no interesan de momento a empresas particulares en concreto; por ello, los recursos con que se cuenta son bastante escasos, tanto desde el punto de vista financiero como humano. Es un nuevo enfoque de la psicología del trabajo que apunta no tanto a predecir, clasificar y redistribuir los recursos humanos, sino a trazar y tantear vías alternativas e innovadoras capaces de transformar las relaciones de producción, competencia y progreso tecnológico-científico. Si se le puede achacar un cierto matiz conservador a los propósitos y logros de la psicología diferencial aplicada al trabajo (hacer ciencia a partir de las divergencias que se observan y vienen dadas), el tratamiento diferencial de las organizaciones podría ser catalogado de innovador en cuanto que intenta adelantarse a la realidad actual, diseñando sistemas de trabajo humano que resuelven funcionalmente los problemas e incongruencias ahora en vigor.

En estos momentos, merced al imperativo japonés, se está asistiendo a un proceso que, a primera vista, puede ser calificado de involución: la des-industrialización de la economía que patrocina la informática de los procesadores. Hasta ahora se tenía claro que la producción de bienes y el avance de la sociedad se nutría de tres fuentes: el trabajo humano, la materia prima y la energía. Está claro ya que un cuarto componente está resultando imprescindible: el manejo de la información. De momento se está entendiendo que la informatización resta puestos de trabajo y genera la actual sociedad de paro. Sin embargo, el futuro comienza a pespuntar de un modo distinto: la informatización exige que se reorganice, a gran escala y en paralelo, el desarrollo máximo de las predisposiciones intelectuales y conocimientos adquiridos por los seres humanos. La sociedad informatizada va a requerir cada vez más personas preparadas para programar y controlar el trabajo de las máquinas. Japón, con gran densidad de población por superficie, cuenta con una de las más altas tasas de empleo del mundo. El «desafío mundial» proclamado por el Grupo de París (Servan-Schreiber, 1980) señala en esta dirección.

¿Cuál puede ser el papel que incumba a los psicólogos del trabajo en estas fronteras laborales que se están abriendo? La sociedad informatizada va a requerir un gran número de trabajadores ahora disponibles que deberán ser formados; aquí se abre un nuevo panorama.

Uno de los capítulos más brillantes de la Psicología Diferencial gira en torno a la «estructura de la inteligencia» estudiada tanto desde la perspectiva de producto como desde la de proceso. Gran parte de estos esfuerzos, que parecían haber desembocado en una vía muerta van a recuperar, en breve, nuevo auge. Está haciéndose evidente la necesidad de hallar nuevo cauce a las capacidades intelectuales del hombre. El psicólogo del trabajo tiene así un nuevo papel que desempeñar de cara a la inminente transformación de tecnologías. Su función podrá ser doble: colaborar en la adaptación (viejo tema) o en el diseño (nuevo enfoque) de las vías que se presagian. En definitiva, es un replanteamiento novedoso del rendimiento. 


\section{CONCLUSION}

Son muchos los aspectos que no se han abordado en estas páginas. No se ha hecho mención ni a las contribuciones de la ergonomía e ingeniería humana al incremento del rendimiento ni se ha aludido a los estudios psicológicos en torno a la mejora del medio ambiente laboral con vistas a una mayor satisfacción y eficiencia humana. Son varios los centros en Inglaterra, Francia y Suecia donde psicólogos del trabajo, mano a mano con otros profesionales, están aportando nuevas orientaciones y procedimientos viables y eficaces en sus tratamientos. Esta exposición podría alargarse hasta convertirla en un libro.

Como se indicaba en el título, se ha pasado revista somera a «la predicción diferencial del rendimiento», poniendo especial énfasis en la reconciliación creciente de los enfoques puramente académicos y de los expresamente profesionales en este área de la psicología del trabajo. Así, según ha quedado evidenciado en las últimas páginas, el desarrollo elegido ha sido predominantemente clásico, centrado en las diferencias. En la última parte se ha preferido abrir las ventanas, a sabiendas de las incongruencias y el desconcierto posible, con la certeza de que el panorama plantea interrogantes para los que de momento no existen respuestas y soluciones claras. $\mathrm{La}$ ciencia y la tecnología se labran nuevas sendas a través del desarrollo de preguntas. Es ahí donde el psicólogo académico y el profesional deberán encajar los inminentes retos.

\section{Referencias}

A. P. A.: Standards for educational and psycbological tests and manuals, Washington, American Psychological Association, 1966, versión española: Normas sobre tests y manuales educativos y psicológicos, Madrid, TEA, 1977.

Alderfer, C. P.: «An empirical test of a new theory of human needs», Organizational Bebavior and Human Performance, 1969, 4, 142-175.

- Existence, relatedness and growth: buman needs in organizational settings, N. Y. Free Press, 1972.

Amon, J.: «Las correlaciones canónicas en Psicología y Sociología», Rev. Psicol. Gral. y Apl., $1974,29,813-819$.

ARgYris, C.: Understanding organizational behavior, Homewood, Dorsey Press, 1961; Integrating the individual and the organization, N. Y. Wiley, 1964, V. esp.: El individuo dentro de la organización, Barcelona, Herder, 1979.

Von BeRTAlanfFy, L.: Robots, men and minds: psychology in the modern world, N. Y. Braziller, 1967; V. esp.: Robots, mentes y bombres, Madrid, Guadarrama, 1974.

Blanco Cotano, J. M.: «Burocracia y personalidad en N. Seisdedos», 16 PF, Monografía Técnica, Madrid, TEA, 1978.

Blum, M. L., y NaYloR, J. C.: Industrial Psycbology, N. Y. Harper \& Row, 1968; V. esp.: Psicología Industrial, México, Trillas, 1976.

Campbell, J. P.; DunNetTET, M. D., y otros: Managerial bebavior, performance and effectiveness, N. Y. McGraw Hill, 1970.

Cattell, R. B.: « $\mathrm{r}_{\mathrm{p}}$ and other coefficients of pattern similarity», Psycbometrika, 1949, 14, 279-298.

- Personality and motivation structure and measurement, N. Y. Wotld Book, 1957;

- «Validity and reliability, a proposed more basic set of concepts», J. of Educ. Psych, 1967, $55,1-22$.

- Personality and Mood by Questionnaire, S. Fco., Jossey-Bass, 1973.

- The Scientific use of factor analysis in Bebavioral and life Sciences, N. Y. Plenum Press, 1978.

- Personality and Learning Tbeory, volume 1, Structure of Personality in its environment; volume 2, A Systems Theory of maturation and structured learning, N. Y. Springer, 1979 y 1980 .

Cattell, R. B., y Butcher, H. J.: The prediction of achievement and creativity, Indianapolis, Bobbs Merrill, 1968.

Cattell, R. B., y Child, D.: Motivation and Dynamic Structure, N. Y. Wiley-Halstead, 1975.

Claxton, G.: Cognitive Psychology: new directions, Londres, Routledge \& Kegan Paul, 1980.

Cuadras Avellana, C., y Sánchez-Turet, M.: «Aplicaciones del análisis multivariante canónico en la investigación psicológica», Rev. Psicol. Gral. y Apl., 1975, 30, 371-381.

Domínguez, P., y CASAs, J. I.: Introducción a la psicosociología del trabajo, Madrid, Pablo del Río, 1979. 
Dunnette, M. D.: Personnel selection and placement, Belmont, Wadsworth, 1966; Handbook of Industrial and organizational psychology, Chicago, Rand McNally, 1976.

Fleishman, E. A.: The structure and measurement of physical fitness, Englewood, N. J. Prentice Hall, 1964.

- «Performance assessment based on a empirically derived task taxonomy», Human Factors, 1967, 9, 349-366.

ForteZa MéndEZ, J. A.: La motivación en el trabajo, Madrid, Marova, 1971.

Forteza Méndez, J. A., y Prieto Zamora, J. M.: «Hacia un nuevo enfoque de la Psicología Diferencial», Estudios de Psicología, 1980, núm. 4.

Ghiseldi, E. E.: «Dimensional problems of criteria», J. of Applied Psychology, 1956, 40, $1-4$.

GIL MuÑoz, C.: Correlación parcial, correlación múltiple, Madrid, INAPP, 1972.

Hammond, D. C., y Stanfield, K.: Multidimensional Psychotberapy, Champaign, IPAT, 1976; V. esp.: Psicoterapia multidimensional, Madrid, TEA, 1981.

Harman, H. H.: Modern Factor Analysis, Chicago, Univ. of Chicago Press, 1976; V. esp.: Análisis Factorial Moderno, Madrid, Saltes, 1980.

Herzberg, F.: «One more time: how do you motivate employees?, Harvard Business Review, $1968,46,53-62$.

Herzberg, F.; Mausner, B., y Snyderman, B.: The motivation to work, N. Y. Wiley, 1959.

HoRN, J. L.: «Significance tests for use with $\mathbf{r}_{\mathbf{p}}$ and related profile statistics, Educ. \& Psych. Measurement, 1961, 21, 363-370.

- «Motivation and dynamic calculus concepts from multivariate experiments», en R. B. Cattell: Handbook of Multivariate Experimental Psychology, Chicago, Rand McNally, 1966, 611-641.

James, L. R.: «Criterion Models and construct validity for criteria», Psychol. Bull., 1973, 80, 75-83.

Korman, A. K.: Industrial and Organizational Psychology, Englewood, N. J. Prentice Hall, 1971; V. esp.: Psicología Industrial y de las Organizaciones, Madrid, Marova, 1978.

LIKERT, R.: The human organization, N. Y. McGraw Hill, 1967; V. esp.: El factor bumano en la empresa, Bilbao, Deusto, 1968.

MarTínez, R.: Variables psicológicas en el rendimiento matemático, Univ. Complutense, 1977, Tesis Doctoral, Madrid.

McCormick, E. J., y Anmerhand, H. L.: Development or worker activity cbeck list for use in ocupational analysis, Lackland, Personnel Lab. Wadd, 1960.

McCormick, E. J., y JeANNERET, P. R.: «A study of job characteristics and job dimensions as based on the position analysis cuestionnaie», J. of Applied Psychol., 1972, 56, 347-368.

McGREGOR, D.: The buman side of enterprise, N. Y. McGraw Hill,1960; V. esp.: El aspecto bumano de las empresas, México, Diana, 1969.

Pérez Velasco, V.: Hacia un nuevo concepto: psicología del trabajo, Madrid, Colegio Doctores y Licenciados en Psicología, 1980, Manuscrito.

Porter, L. W., y LAwler, E. E.: Managerial attitudes and performance, Homewood, Dorsey Press, 1968.

Prieto Zamora, J. M.: «Perfil de personalidad de un grupo de estudiantes de enfermeras», Rev. Psicol. Gral. y Aplic., 1977, 32, 887-898.

- Estudio comparativo de las formas $A-B$ del $16 \mathrm{PF}$, de R. B. Cattell, en su adaptación española TEA, Madrid, Univ. Compl., 1977, Memoria de Licenciatura no publicada.

- «La Inteligencia General como factor B en el 16 PF, Rev. Psicol. Gral. y Aplic., 33, 1978, 463-474.

- «Mayor fiabilidad y validez, formas A+B, en N. Seisdedos, 16 PF, Monografía Técnica, Madrid, TEA, 1978.

- «Personalidad, pareja y familia, Diagnóstico multifactorial de la pareja», Rev. Psicol. Gral. y Aplic., 1979, 34, 1089-1098.

- Estructura de la personalidad bumana a partir de datos $Q$ en adultos: estudio factorial con muestras españolas, Madrid, Editorial Universidad Complutense, 1980.

- «La personalidad, ¿paradigma o sistema?, Estudios de Psicologia, 1980, núm. 3, 97-108.

- «Factores de segundo orden en la personalidad a partir de datos $Q$ en adultos españoles», Rev. Psicol. Gral. y Apl., 1981, 36, 33-52.

ScheIn, E. H.: Organizational Psycbology, Englewood, Prentice Hall, 1965; V. esp.: Psicología de las Organizaciones, Madrid, Castillo, 1973.

SeIsdedos, N.: 16 PF, Monografía Técnica, Madrid, TEA, 1981, 2: ed. revisada.

Seisdedos, N., y Prieto Zamora, J. M.: «La medición de la personalidad a través de datos Q", en N. Seisdedos, 16 PF Monografía Técnica, Madrid, TEA, 1981.

Servan Screiber, J. J.: El Desafío Mundial, Barcelona, Plaza-Janés, 1980.

Smiтh, P. C.: «The problem of criteria», en M. D. Dunnette, Handbook of Industrial and Organizational Psycbology, Chicago, Rand Mc. Nally, 1976, 745-775.

Tномpson, D. C.: «The effective utilization of Personality constructs in Applied situations», en R. B. Cattell y R. M. Dreger: Handbook of Modern Personality Tbeory, Washington, Hemisphere, 1977, 709-720.

Vroom, V. H.: Work and Motivation, N. Y. Wiley, 1964. 